\title{
The relative age effect in the 2013 FIFA U-17 Soccer World Cup competition
}

\author{
Ridha Sallaoui ${ }^{1,2, ~}{ }^{,}$, Karim Chamari ${ }^{3}$, Moktar Chtara ${ }^{4}$, Youssef Manai ${ }^{1}$, Mourad Ghrairi ${ }^{2}$, \\ Mohcine Belhaouz ${ }^{2}$, Abdullah Baroon ${ }^{2}$ \\ ${ }^{1}$ Alahli Sports Club of Dubai, Dubai, United Arab Emirates \\ ${ }^{2}$ UAE Football Association, Dubai, United Arab Emirates \\ ${ }^{3}$ Athete Health and Performance Research Center, Aspetar, Doha, Qatar \\ ${ }^{4}$ National Center of Medicine and Sciences in Sports, Tunisia
}

\section{Email address:}

rida.sallaoui@laposte.net (R. Sallaoui)

\section{To cite this article:}

Ridha Sallaoui, Karim Chamari, Moktar Chtara, Youssef Manai, Mourad Ghrairi, Mohcine Belhaouz, Abdullah Baroon. The Relative Age Effect in the 2013 FIFA U-17 Soccer World Cup Competition. American Journal of Sports Science.

Vol. 2, No. 2, 2014, pp. 35-40. doi: 10.11648/j.ajss.20140202.15

\begin{abstract}
Purpose: The purpose of this study was to check the eventual existence of any Relative Age Effect (RAE) in the recent 2013' FIFA Male Under-17 (U-17) World Cup Football tournament. The data pertaining to the players who participated in to that event were collected from the FIFA website. They included the players' dates of birth (day, month and year) and position (goalkeeper, defender, midfielder or striker).The distributions of birth months were significantly different with more players born in the early months of the year compared with the later months. For the entire cohort of players, $38.7 \%$ were born in the first quarter of the year while only $10.5 \%$ were born in the last 3 months in the same year. This relative age effect held for all FIFA-designated teams except for the Nigeria and the Côte d'Ivoire having shown a reverse relative age effect. The results of this investigation show that at the highest level of youth soccer, the RAE still exists and is a strong bias toward inclusion of players born early in the concerned year.
\end{abstract}

Keywords: Youth Soccer, Reverse Relative Age Effect, Birth-Date

\section{Introduction}

The FIFA Under-17 (U-17) World Cup tournament was originally founded as the FIFA U-16 World Championship, which later changed to the FIFA U-17 World Championship and has been known by its current name since 2007 . The 2013 FIFA U-17 World Cup was the fifteenth tournament of that event [1]. The 2013 tournament was hosted by the Emirates from $17^{\text {th }}$ of October to $8^{\text {th }}$ of November with the participation of 24 nations and the schedule of 52. The tournament was organized based on chronological age, which is a selection criterion used to safeguard equal opportunities [1]. However, considerable complexities can arise from this, due to significant interindividual variations relating to growth and maturity both in infancy and, most importantly, in adolescence [1]. The difference in chronological age between children in a single age group is known as relative age and its consequences are known as the Relative Age Effect (RAE). The RAE in sport was first noted among elite ice hockey players in Canada in the early 1980 s $[3,4$,$] and is a widely researched area, with$ literally hundreds of papers published in the academic literature. The first review article on the RAE by Musch and Grondin [5] reviewed over 80 previous studies which proposed that RAEs only manifest themselves when a significant degree of competition is present. More recently, Cobley and colleagues [6] conducted a meta-analytical review of 38 studies across 14 sports and 16 countries. Both of these studies identified a consistent prevalence of the RAE. In addition, sports such as ice hockey [7], American football[8], baseball[9], basketball [10,11], cricket [12], and tennis $[13,14]$ are breeding grounds for RAEs because weight, height and strength are important in these sports. The RAE is not apparent in sports such as gymnastics, dance, golf, and table tennis $[15,16]$ as other factors are more important, such as technical ability (or motor skill), flexibility, speed and precision of movement rather than absolute strength or force. Rather, having a large body size or mass may present a disadvantage to the athlete in these types of sport [10]. 
The issue of RAE in soccer has been analyzed with some studies focusing on the professional leagues in countries such as Belgium [17], England [14] or Germany [20]. Other research studies have sought to contrast data from several professional clubs. One study was conducted by Verhulst [21], who analyzed data from several European leagues such as the French, Belgian, and Dutch leagues. Another study was carried out by Musch and Hay [22], who assessed the birth dates of professional players in the Australian, Brazilian, German, and Japanese leagues. Both studies revealed a high and significant incidence of the RAE, evidenced by the fact that more than $55 \%$ of players were born in the first six months of the year. This type of analysis has also been conducted on international competitions. For instance Barnsley et al. [23] carried out a research on the 1990 soccer senior's World Cup and showed that some $55 \%$ of players in full national teams were born in the first half of the year, that figure rising to an average of $79 \%$ in both the U-17 and U-20 World Cups, indicating a higher incidence of the RAE. Williams JH [24] sought to determine if a RAE existed in the most recent six FIFA U-17 World Cup competition from 1997 to 2007. The results of this investigation showed that at the highest level of youth soccer there was a strong bias towards the inclusion of players born earlier in the concerned' selection-year.

Thus, the aim of this study was to identify whether a RAE still existed in the recent 2013 FIFA U-17 World Cup male soccer tournament.

\section{Methods}

\subsection{Procedures}

To determine the existence of any RAE in the FIFA U-17 Soccer competition, player birth-dates were collected to reflect both their birth month and quarter. All age-group competitions in the FIFA youth Soccer World Cup competition are based on a player's age in the calendar year; for example, a player turning $n$ years old between 1 January and 31 December of a year will be eligible for the "Undern" competition..A total of 504 players from 24 countries participated in this competition

\subsection{Birth Date Distribution}

The data pertaining to the players who participated in the 2013 FIFA U-17 World Cup was collected from the FIFA website. The data included the players' dates of birth (day, month, and year) and position: goalkeeper (GK), defender (DF), midfielder (MF), or striker (FW). To examine the birth date distribution in this competition, players were divided into 4 quarters. $1^{\text {st }}, 2^{\text {nd }}, 3^{\text {rd }}$ and $4^{\text {th }}$ Quarter corresponding to birth dates in 1996 The quarter are defined as: $1^{\mathrm{s}}$ quarter ${ }^{\mathrm{t}}=$ birth dates in: January to March, $2^{\text {nd }}$ quarter $=$ birth dates in: April to June, $3^{\text {rd }}$ quarter $=$ birth dates in: July to September, and $4^{\text {th }}$ quarter $=$ birth dates in: October to December,.
The Q5 corresponding to under-aged who birth dates in 1997, 1998 and 1999.

\subsection{Statistical Analyses}

All statistical analyses were performed using the SPSS statistical software package (SPSS Inc., Chicago, IL, USA, 20.0). The birth date distributions were tested using chisquare statistics. Statistical significance was tested at the 5\% level.

\subsection{Data Analysis}

To compare the quarter, chi-square goodness-of-fit tests were used to compare differences between the observed and expected birth-date distributions across the quarters of the selection year.

\section{Results}

\subsection{Relative Age Effects}

Table 1 shows the birth-date distribution by quartile and semester for the total sample, and for the four positions of players. Overall, $38.7 \%$ of the players were born in the first quarter, while only $10.5 \%$ of the players were born in the fourth (i. e., last) quarter. Nigeria and the Côte d'Ivoire showed an inverse trend with birth month distributions that favored younger players. Indeed,-these nations had $26.09 \%$ the players born in the fourth quarter while Nigeria has $4.35 \%$ and the Côte d'Ivoire has $17.39 \%$ were born in the first quarter.

Table 1. Number of players born in each of the four quarters of the year and the Under-age according to players 'positions (n: \%).

\begin{tabular}{lllllll}
\hline \multirow{2}{*}{ Team } & $\begin{array}{l}\mathbf{1}^{\text {st }} \\
\text { Quarter }\end{array}$ & $\begin{array}{l}\mathbf{2}^{\text {nd }} \\
\text { Quarter }\end{array}$ & $\begin{array}{l}\mathbf{3}^{\text {rd }} \\
\text { Quarter }\end{array}$ & $\begin{array}{l}\mathbf{4}^{\text {th }} \\
\text { Quarter }\end{array}$ & $\begin{array}{l}\mathbf{5} \mathbf{Q} \\
\text { Under-age }\end{array}$ & $\mathbf{X}^{2}$ \\
\hline \multirow{2}{*}{ G.K } & 20 & 19 & 12 & 9 & 12 & \\
& $(27.8 \%)$ & $(26.4 \%)$ & $(16.7 \%)$ & $(12.5 \%)$ & $(16.7 \%)$ & 6.5 \\
\multirow{2}{*}{ DF } & 62 & 35 & 23 & 16 & 15 & \\
& $(41.1 \%)$ & $(23.2 \%)$ & $(15.2)$ & $(10.6 \%)$ & $(9.9 \%)$ & $50.3 * * *$ \\
\multirow{2}{*}{ MF } & 74 & 39 & 23 & 18 & 27 & \\
& $(40.9 \%)$ & $(21.5 \%)$ & $(12.7 \%)$ & $(9.9 \%)$ & $(14.9 \%)$ & $55.9^{* * *}$ \\
\multirow{2}{*}{ FW } & 39 & 24 & 12 & 10 & 15 & \\
& $(39 \%)$ & $(24 \%)$ & $(12 \%)$ & $(10 \%)$ & $(15 \%)$ & $28.3 * * *$ \\
\multirow{2}{*}{ Total } & 195 & 117 & 70 & 53 & 69 & \\
& $(38.7 \%)$ & $(23.2 \%)$ & $(13.9 \%)$ & $(10.5 \%)$ & $(13.7 \%)$ & $132.7 * * *$ \\
\hline
\end{tabular}

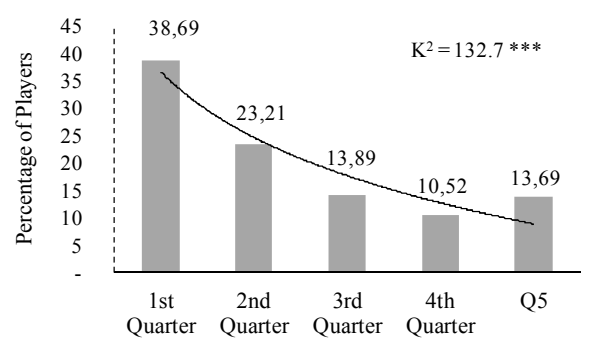

Figure 1. Percentage of players born in each of the four quarters of the year. 
The birth date distribution of the soccer players differed significantly (total groups, $\chi^{2}=132.7, p<0.001$ ) (Figure1), and reflects a skewed distribution with a greater number of players born at the beginning of the selection year and a lower number of players born later in the year.

For this U-17 tournament concerning players born in 1996, several teams had under-aged players (born in: 1997 to 1999). Four teams had more than $20 \%$ of under-aged players: Nigeria, Cote d'ivoire, Japan, and Panama with percentages of $43.48 \%, 39.13 \%, 26.09 \%$ and $21.74 \%$, respectively.

We also sought to determine whether aspects such as the age group the player competes or their position on the field had any affect. The percentage of players born in the first quarter of the selection year varied between $27.8-41.1 \%$, and $9.9-16.7 \%$ for the last quarter. The birth-date distribution of the position of the soccer players differed significantly (defender (DF), $\chi^{2}=50.3, \mathrm{p}<0.001$; midfielder (MF), $\chi 2=55.9, \mathrm{p}<0.001$; forward $(\mathrm{FW}), \chi^{2}=$ 28.3, $\mathrm{p}<0.001)$. Moreover, there was no influence of age class on the position of Goal Keeper (GK) $\left(\chi^{2}=6.5\right.$, $\mathrm{P}>0.05$ ) (Table 1).

\section{Discussion}

The birth-date distributions in the recent 2013 FIFA U-17 Soccer World Cup competition were examined. All countries showed a significant RAE, except for the Nigeria and the Côte d'Ivoire have shown a reverse relative age effect

Previously, researchers have suggested that the existence of, and possibly the increase in, the prevalence of the RAE in soccer is driven by different mechanisms and hypotheses [17]. Among the hypotheses most widely used to explain these observed differences is the maturational theory, which is based on potential maturational differences attributable to age variations in a single class or age group $[18,2,27$, $28,29,30]$. This theory suggests that when players are selected for a team, there is a bias towards selecting boys born in the first months of the year. These players possess an advanced maturational age for their selection year, which gives them a range of anthropometric advantages over other younger players born in the last months of the same year. Numerous studies seem to suggest that both anthropometric size and conditional capabilities are linked to maturational development and are conditioned by age [2, 31]. In this context, Martin et al. [32] have shown that neurological maturation can manifest itself in different capabilities such as the self-regulation of attention, emotion and other functions such as memory [33], selective attention [33] and certain aspects of metacognition [35] and inhibition control [36]. In addition to this, Robin Van den Honert [25] has shown that psychological effects are factors that influence the RAE in youths. Correlations between the perception of competence and actual competence (as measured by teachers' ratings of sport performance) reveal that children are able to more accurately perceive their own competence with age (i.e. 10 to 13 year olds are more accurate than 8 to 9 year olds). Children with a higher perceived competence enjoy participation more than those with a lower perceived competence, leading to relatively older children being advantaged by a higher relative age, and who are therefore more likely to continue participating.

The maturational theory hypothesis suggests that physical development is an important factor in sports where advanced maturation promotes performance (e.g. forwards in rugby union, goalkeepers in ice hockey who wear heavy equipment and have the highest physical demand), and in the field positions within sports in which the RAE is most pronounced. Soccer is one of these sports, in which speed, strength, agility, ball-control, and co-ordination are all important requirements [25].

Musch and Grondin [5] have described another series of factors related to the sport setting which clearly encourage the RAE, including the level and strength of competition. This means that in less popular sports, such as volleyball [16], the effect is less prominent or non-existent. Other factors include the popularity of sport, the system of twoyear age categories, early specialization in the selected sport, the expectations of the coaches responsible for the evaluation and/or selection processes, and the date the school year starts.

The general birth-date distribution of the 2013 U-17 World Cup competition showed that $38.7 \%$ of the players were born in the first quarter of the selection year and only $10.5 \%$ were born in the fourth quarter of the selection year. The issue of RAE in soccer has been a research topic since the early 1990s. Dudink [14] noted very strong RAEs in senior professional soccer in the Netherlands and England. Other research studies have sought to contrast data from several professional clubs, such as the one conducted by Verhulst [21], in which data from several European leagues such as the French, Belgian, and Dutch leagues were analyzed [22], also assessed the birth dates of professional players inthe Australian, Brazilian, German and Japanese leagues. It results that the RAE seems independent of cultural and climatic effects, as well as different cut-off dates e.g. Germany and Brazil used a cutoff date of 1 August for their "football year", Japan used 1 April. Australia used 1 January up to 1988, after which the cut-off was changed to 1 August to comply with FIFA regulations, and subsequently changed back to 1 January in 1995. These studies revealed a high incidence of RAEs, evidenced by the fact more than $55 \%$ of players were born in the first six months of the year. In line with previous studies examining the RAE in senior soccer in Germany [37] and in Spain [38], the birth-date distributions of professional soccer players in ten European countries were examined in the 2000-2001 and 2010-2011 competitive seasons, this study showed that in the 2000-2001 competitive seasons, all countries, with the exception of Portugal and Spain, showed a significant RAE. In the 20102011 season, no RAE was evident in Portugal, there has been 
no decrease in the prevalence of RAEs during the last decade [26]. The birth-date distribution of the 2010-2011 competitive season showed that $31.9 \%$ of the players were born in the first quarter of the selection year and only $18.4 \%$ in the last quarter compared with $29.3 \%$ and $19.8 \%$ in the 2000-2001 season, respectively[26]. These data suggest that despite solutions being proposed in the literature there has been little impact on this RAE effect. Conversely, Spain showed no RAEs in the 2000-2001 competitive seasons, yet a significant effect was noted in the 2010-2011 competitive season [38]. Similarly, Helsen et al. [19] noted RAEs in international youth teams (i.e. U-15 to U-18 years of age) reflecting a disproportionate number of relatively older players. Jimenez and Pain [38] found a RAE in the first and second divisions in Spain as well as in youth soccer.

A more detailed analysis within the age categories and the positions of players on the field of the present study revealed that the percentage of players born in the first quarter of the selection year varied between 27.8 and $41.1 \%$, and between 9.9 and $16.7 \%$ for the last quarter. The birth date distribution of the position of soccer players differed significantly in three positions (defender (DF), midfielder (MF) and striker (FW). Moreover, there was no influence of age class on the position of goal keeper (GK).

It has been well documented that the RAE is more relevant in high-level team's senior and youth. The date of birth of $36-50 \%$ of soccer players was within the first 3 months of the year, whereas around $4-17 \%$ was within the last 3 months of the year [39, 40, 41, 42]. This type of analysis has also been conducted for international competitions. For example, Barnsley et al. [23]carried out a study on the 1990 senior soccer World Cup and discovered that some $55 \%$ of players in full national teams were born in the first half of the year, that figure rising to an average of $79 \%$ in both the U-17 and U-20 World Cups, indicating a higher incidence of RAEs. Similar observations were made in a series of studies on young footballers playing for both national teams $[23,13,19]$. In a recent study, Williams et al. (2010) sought to determine if RAEs existed in the FIFA U17 World Cup competition from 1997 to 2007. The results of this investigation showed that at the highest level of youth soccer, there is a strong bias towards the inclusion of players born earlier in the selection year with a significant RAE effect on all the studied tournaments.

The present study shows that Nigeria and Côte d'Ivoire displayed a reverse RAE. This could be due to several factors. First, there may be the existence of the potential for error in reporting actual birth dates [24]. In this context, only about half of the births for children under 1-year-old are registered in certain African zones. For instance, a study of vital registries in Cameroon indicates that only 33\% of births could be confirmed by a birth certificate since the documents are held by the father [43]. Secondly, the two concerned countries were amongst the ones displaying more than $20 \%$ under-aged players. This fact could have influenced this reverse effect. The reason for a youngsters' team to include under-aged players comes from the very high level/skills of the concerned players. As discussed above, usually, physical stature makes the difference in the youngsters' categories. Nevertheless, soccer does not rely only on physical performance. In this context, some technical and/or tactical capabilities allow "smaller stature" players to emerge and be a key member in the squad.

Various solutions have been proposed for the RAE issue in some sports. These include changing the structure of the competition [44, 45, 46]; however, this would be very difficult to implement. Yet it would be more feasible for the technical directors of clubs and sporting academies to implement solutions designed to change the way they operate internally, such as grouping teams together by quarterly periods, which depending on the sports and club's sizes would be quite difficult to implement or to reducing the pressure that results exert on players taking part in competitions. The sports responsible must make a special long-term commitment to themselves because the real potential of a soccer player will not become apparent until they reach the end of their maturation process [47].

\section{Conclusion}

The collected data revealed the existence of RAEs in youth soccer at the recent 2013 FIFA U-17 World Cup tournament. The distribution of birth months more players born in the early months of the year compared with the later months. For the entire cohort of players, 38.7\% were born in the first quarter of the year while only $10.5 \%$ were born in the last 3 months. A small portion of this effect seems to be due to the physical stature of the players. This relative age effect (RAE) was observed for all participating countries except Nigeria and Cote d'Ivoire. The results of this investigation confirmed that the highest level of youth soccer, there is a strong bias toward inclusion of players born early in the selection year.

\section{Acknowledgments}

The authors gratefully acknowledge Mr Abdullah Saeed Al Naboodah, Chairman of Al Ahli sport Club of Dubai and $\mathrm{Mr}$ YousefYaqoub Al Serkal, president of the UAE football association for providing necessary support during this research work.

\section{References}

[1] Info: Plein soleil sur les futures étoiles Availableat: http://www_fr.fifa.com/u17worldcup. Cited: Oct 17, 2013.

[2] Malina, R., Bouchard, C., \& Bar-Or, OGrowth, maturation, and physical activity (2nd ed.). Champaign, IL: Human Kinetics. . (2004)

[3] Barnsley, R. H., Thompson, A. H., \&Barnsley, P. E. Hockey success and birth-date: The relative age effect. Journal of the Canadian Association for Health, Physical Education and Recreation, 1985; 51: 23-28. 
[4] Grondin, S., Deshaies, P. and Nault, L.P. Quarter of birth and participation in hockey and volleyball. La Revue Que'becoise de l'Activite' Physique.1984; 2: 97-103.

[5] Musch, J. and Grondin, S. Unequal competition as an impediment to personal development: a review of the relative age effect in sport. Developmental Review.2001; 21(2): 147-167.

[6] Cobley, S., Baker, J., Wattie, N., \& McKenna, J. Annual age-grouping and athlete development: A meta-analytical review of relative age effects in sport. Sports Medicine.2009; $39: 235-256$.

[7] Grondin. S., \& Trudeau, F. Date de naissance et ligue nationale de hockey: analyses en fonction de différents paramètres. Revue des Sciences et Techniques des Activités Physiques et Sportives. $1991 ; 26: 37-45$.

[8] Glamser, F. D., \&Marciani, L. M. The birth-date effect and college athletic participation: some comparisons. Journal of Sport Behavior.1990; 15: 227-237.

[9] Thompson, A. H., Barnsley, R. H., \&Stebelsky, G. Born to play ball: The relative age effect and major league baseball. Sociology of Sport Journal.1991; 8: 146-151.

[10] Delorme, N., Boiche, J., \&Raspaud, M. Relative age effect in female sport: A diachronic examination of soccerplayers. Scandinavian Journal of Medicine and Science in Sports.2010; 20: 509-515.

[11] Schorer, J., Neumann, J., Cobley, S. P., Tietjens, M., \& Baker, J. Lingering effects of relative age in basketball players' post athletic career. International Journal of Sports Science \& Coaching.2011; 6(1): 143-147.

[12] Edwards, S. Born too late to win?. [Letter to the Editor]. Nature. 1994; 370- 186.

[13] Baxter-Jones, A. Growth and development of young athletes. Should competition levels be age related? Sports Medicine.1995; 20: 59-64.

[14] Dudink, A. D. Birth date and sporting success. Nature. 1994; $368,592$.

[15] Cote', J., Macdonald, D.J., Baker, J., \& Abernethy, B. When "where" is more important than "when": birthplace and birthdate effects on achievement of sporting expertise. Journal of Sports Sciences.2006; 24: 1065-1073.

[16] Van Rossum, J. H. Relative age effect revisited: Findings from the dance domain. Perception and Motor Skills. 2006; 102: $302-308$

[17] Helsen, W.F., Janet, L., Starkes, J.L. and Winckel, J.V. The influence of relative age on success and dropout in male soccer players. American Journal of Human Biology.1998; 12: 729-735.

[18] Helsen, W. F., Hodges, N. J., Van Winkel, J., \&Starkes, J. L. The roles of talent, physical precocity and practice in the development of soccer expertise. Journal of Sports Sciences.2000; 18: 1-10.

[19] Helsen, W. F., Van Winkel, J., \& Williams, A. M. The relative age effect in youth soccer across Europe. Journal of Sports Sciences.2005; 23: 629-636.

[20] Bäumler, G. The relative age effect in soccer and its interaction with chronological age. Sportonomics.2000; 6(1):
25-30.

[21] Verhulst, J. Seasonal birth distribution of West European soccer players: A possible explanation. Medical Hypotheses. 1992; 38: 346-348.

[22] Musch, J., \& Hay, R. The relative age effect in soccer: Cross-cultural evidence for a systematic discrimination against children born late in the competition year. Sociology of Sport Journal.1999; 16: 54-64.

[23] Barnsley, R.H., Thompson, A.H. and Legault, P. Family planning: Football style. The relative age effect in football. International Review for the Sociology of Sport.1992; 27(1) $77-88$.

[24] Williams JH. Relative age effect in youth soccer: analysis of the FIFA U17 World Cup competition. Scand J Med Sci Sports. 2010; 20(3):502-8.

[25] Robin van den Honert. Evidence of the relative age effect in football in Australia. Journal of Sports Sciences.2012; 30(13): 1365-1374

[26] Werner F. Helsen, Joseph Baker , StijnMichiels , JoergSchorer, Jan Van winckel\& A. Mark Williams. The relative age effect in European professional soccer: Did ten years of research make any difference? Journal of Sports Sciences.2012; 30:15,1665- 1671 .

[27] Malina, R.M. Talent identification and selection in sport. Technique.1999; 19: 1619.

[28] Philippaerts RM, Vaeyens R, Janssens M, Van Renterghem B, Matthys D, Craen R, Bourgois J, Vrijens J, Beunen G, Malina RM. The relationship between peak height velocity and physical performance in youth soccer players. J Sports Sci. 2006;24(3):221-30.

[29] Reilly, B.F. Anthropometric and physiological predispositions for elite soccer. Journal of Sports Sciences.2000; 18, 669-683.

[30] Simmons, C., \&Paull, G. C. Seasonof-birth bias in association football. Journal of Sports Sciences.2001; 19: $677-686$.

[31] Malina, R., Bouchard, C., \& Bar-Or, O. (2004). Growth, maturation, and physical activity (2nd ed.). Champaign, IL: Human Kinetics.2004.

[32] Martin, R.P. Clanton, G. and Moon, K. Season of birth is related to child retention rates, achievement, and rate of diagnosis of specific LD. Journal of Learning Disabilities.2004; 37(4): 307-317.

[33] Siegler, R.S. Children's thinking: Englewood Cliffs, NJ: Prentice Hall. 1991.

[34] Miller, P.H. The development of strategies in selective attention. In: Children's strategies: Contemporary views of cognitive development. Ed: Bjorklund, D.F. Hillsdale, NJ: Erlbaum.1991: 157- 184.

[35] Garner, R. Children's use of strategies in reading. In: Children's strategies: Contemporary views of cognitive development. Ed: Bjorklund, D.F. Hillsdale, NJ: Erlbaum.1991: 245-268 (English abstract).

[36] Barkley, R.A. Attention-deficit hyperactivity disorder: A handbook for diagnosis and treatment. New York: Guilford Press. 1998. 
[37] Cobley, S. P., Schorer, J., \& Baker, J. Relative age effects in professional German soccer: A historical analysis. Journal of Sports Sciences.2008 26: 1531-1538.

[38] Jime'nez, I. P., \& Pain, M. T. (2008). Relative age effect in Spanish association football: Its extent and implications for wasted potential. Journal of Sports Sciences.2008; 26, 9951003

[39] Carling, C., le Gall, F., Reilly, T., \& Williams, A. M. Do anthropometric and fitness characteristics vary according to birth date distribution in elite youth academy soccer players? Scandinavian Journal of Medicine and Science in Sports.2009; 19: 3-9.

[40] Gil, S., Ruiz, F., Irazusta, A., Gil, J., \&Irazusta, J. Selection of young soccer players in terms of anthropometric and physiological factors. The Journal of Sports Medicine and Physical Fitness.2007; 47, 25-32.

[41] Gravina, L., Gil, S. M., Ruiz, F., Zubero, J., Gil, J., \&Irazusta, J. Anthropometric and physiological differences between first team and reserve soccer players aged 10-14 years at the beginning and end of the season. Journal of Strength and Conditioning Research.2008; 22: 1308-1314.
[42] Augste, C., \& Lames, M. The relative age effect and success in German elite U-17 soccer teams. Journal of Sports Sciences.2011; 29: 983-987.

[43] Ndong I, Gloyd S, Gale J. An evaluation of vital registers as sources of data for infant mortality rates in Cameroon.Int $\mathrm{J}$ Epidemiol 1994: 23: 536-539.

[44] Hurley, W., Lior, D. and Tracze, S. (2001) A proposal to reduce the agediscrimination in Canadian minor hockey. Journal of SportManagement. 2001; 16(3), 250.

[45] Glamser, F. D. and Vincent, J. The relative age effect among elite american youth soccer players. Journal of Sport Behavior.2004; 27(1): 31-38.

[46] Garcia, V. and Salvadores, J. The relative age effect in football. Training Fútbol. 2005, 115: 36-42.

[47] Gutierrez Diaz Del Campo D, Pastor Vicedo JC, Gonzalez Villora S, Contreras Jordan OR. The relative age effect in youth soccer players from spain. J Spoort Sci Med. 2010, 1(9): 190-198. 